\section{(2) \\ BRAZIULIAN JOURNAL \\ OF MEDICAL AND BIOLOGICAL RESEARCH}

www.bjournal.com.br
ISSN 0100-879X

Volume 45 (7) 565-680

July 2012

CLINICAL INVESTIGATION

Braz J Med Biol Res, July 2012, Volume 45(7) 583-590

doi: 10.1590/S0100-879X2012007500086

Development of two potential diagnostic monoclonal antibodies against human cytomegalovirus glycoprotein B

Fan Jun, Li Minhuan, Ma Yadan, Huang Yaping, Liang Hanying, Hu Jianhua, Yao Hangping and Ma Weihang

The Brazilian Journal of Medical and Biological Research is partially financed by

\section{惡CNPq}

da Ciência e Tecnologia

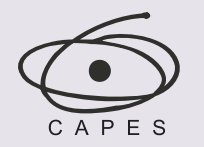

Ministério da Educação

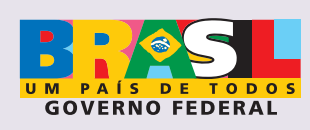

D TAPESP

Institutional Sponsors

$\oplus$ SHIMADZu UNICAMP

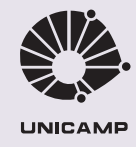

GOVERNO FEDERAL

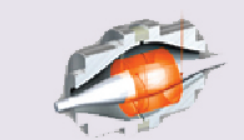

plore High - Performance MS Orbitrap Technology In Proteomics \& Metabolomics analitica $\underset{\text { analiticaweb.com.br }}{\text { Thermo }}$ S I E N I FIC

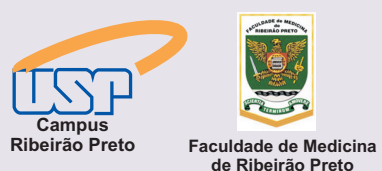

de Ribeirão Preto

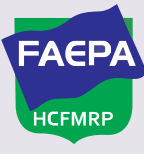




\title{
Development of two potential diagnostic monoclonal antibodies against human cytomegalovirus glycoprotein B
}

\author{
Fan Jun, Li Minhuan, Ma Yadan, Huang Yaping, Liang Hanying, Hu Jianhua, \\ Yao Hangping and Ma Weihang
}

State Key Laboratory for Diagnosis and Treatment of Infectious Diseases, First Affiliated Hospital, School of Medicine, Zhejiang University, Hangzhou, China

\begin{abstract}
Human cytomegalovirus glycoprotein $\mathrm{B}(\mathrm{gB})$ represents a target for diagnosis and treatment in view of the role it plays in virus entry and spread. Nevertheless, to our knowledge, rare detection of a gB antigen has been reported in transplant patients and limited information is available about diagnostic gB monoclonal antibodies (mAbs). Our aim was to develop gB mAbs with diagnostic potential. Hydrophilic gB peptides (ST: amino acids 27-40, SH: amino acids 81-94) of favorable immunogenicity were synthesized and used to immunize BALB/c mice. Two mAbs, named ZJU-FH6 and ZJU-FE6, were generated by the hybridoma technique and limited serial dilution and then characterized by indirect ELISA, Western blotting, immunoprecipitation, and immunohistochemical staining. The mAbs displayed high titers of specific binding affinities for the ST and SH synthetic peptides at an mAb dilution of 1:60,000 and 1:240,000, respectively. Western blotting and immunoprecipitation indicated that these mAbs recognized both denatured and native gB of the Towne and AD169 strains. The mAbs, when used as the primary antibody, showed positive staining in cells infected with both Towne and AD169 strains. The mAbs were then tested on patients submitted to allogeneic hematopoietic stem cell transplantation. The gB antigen positivity rates of the patients tested using ZJU-FH6 and ZJU-FE6 were 62.0 and $63.0 \%$, respectively. The gB antigen showed a significant correlation with the level of pp65 antigen in peripheral blood leukocytes. In conclusion, two potential diagnostic gB mAbs were developed and were shown to be capable of recognizing $\mathrm{gB}$ in peripheral blood leukocytes in a reliable manner.
\end{abstract}

Key words: Human cytomegalovirus; Glycoprotein B; Monoclonal antibody; Antigen detection; Transplantation

\section{Introduction}

Human cytomegalovirus (HCMV), which belongs to the subfamily Betaherpesvirinae, continues to be an important pathogen in immunocompromised individuals (1) despite a decrease in the morbidity and mortality of post-transplant HCMV disease with routine antiretroviral therapy.

Glycoprotein B ( $\mathrm{gB})$, one of the most important envelope glycoproteins of HCMV, is implicated in virus entry, cell-tocell spread (2), and the fusion of infected cells (3). Therefore, detecting $\mathrm{gB}$ antigen in patients with HCMV infection may facilitate the monitoring of the infection. Nevertheless, to our knowledge, rare detection of a $\mathrm{gB}$ antigen has been reported in transplant patients. In long-standing past research, gB has been demonstrated to be a significant target for both humoral and cellular immune responses (4-6). Antibodies against $\mathrm{gB}$ have been of interest because of their thera- peutic potential for neutralization $(7,8)$. However, limited information is available about the diagnostic potential of gB monoclonal antibodies (mAbs).

In this study, two potential diagnostic mAbs to gB were generated. The HCMV strains Towne and AD169 were used to analyze the specificity of the mAbs prepared. Specimens from patients submitted to allogeneic hematopoietic stem cell transplantation (allo-HSCT) were used to demonstrate the diagnostic efficacy of the mAbs.

\section{Material and Methods}

\section{Animals}

BALB/c mice (6-8 weeks old) were purchased from the Shanghai Laboratory Animal Center of the Chinese

Correspondence: Fan Jun, State Key Laboratory for Diagnosis and Treatment of Infectious Diseases, First Affiliated Hospital, School of Medicine, Zhejiang University, 79 Qingchun Road, Hangzhou, 310003, China. Fax: +086-0571-8723-6459.

E-mail: fanjunyz@163.com

Received January 2, 2012. Accepted May 7, 2012. Available online May 25, 2012. Published July 2, 2012. 
Academy of Sciences (Shanghai, China) and housed under pathogen-free conditions. All experiments were conducted according to guidelines of the Animal Ethics Committee of Zhejiang University.

\section{Peptides}

Hydrophilic sequences of favorable immunogenicity containing 14 amino acids of HCMV gB were screened. Peptides (HuaAn Biotechnology Co., China) ST (amino acids 27-40 of the Towne strain gB: STRGTSATHSHHSS, GenBank accession No. M60929), and SH (amino acids 81-94 of the AD169 strain gB: SHATSSTHNGSHTS, GenBank accession No. X04606) were synthesized and partly cross-linked with keyhole limpet hemocyanin (KLH) to enhance their immunogenicity. The molecular masses of the peptides were 3998.2 and 1513.5 Da, respectively, and their purity was 95.1 and $90.3 \%$, respectively.

\section{Cell culture and lysate preparation}

MRC- 5 cells (American Type Culture Collection, USA) were cultured to confluence, and then scraped and lysed at $4^{\circ} \mathrm{C}$ for 40 min with cell lysis buffer (Cell Signaling Technology, USA) containing $20 \mathrm{mM}$ Tris- $\mathrm{HCl}, \mathrm{pH} 7.5,150 \mathrm{mM} \mathrm{NaCl}$, $1 \mathrm{mM} \mathrm{Na}{ }_{2}$ EDTA, $1 \mathrm{mM}$ EGTA, 1\% Triton, $2.5 \mathrm{mM}$ sodium pyrophosphate, $1 \mathrm{mM} \beta$-glycerophosphate, $1 \mathrm{mM} \mathrm{Na}_{3} \mathrm{VO}_{4}$, and $1 \mu \mathrm{g} / \mathrm{mL}$ leupeptin. All insoluble material was removed by centrifugation at $8000 \mathrm{~g}$ for $10 \mathrm{~min}$. Protein concentration was determined using a BCA protein assay kit (Pierce, USA) with bovine serum albumin (BSA) as the standard. To prepare samples of viral protein, MRC- 5 cells were infected with HCMV strains Towne and AD169 (American Type Culture Collection) at a multiplicity of infection (MOI) of 1.0 for 3 days at $37^{\circ} \mathrm{C}(9)$, after which the proteins were purified as described above.

\section{Generation and purification of monoclonal antibodies}

BALB/c mice were immunized subcutaneously four times $(100 \mu \mathrm{g} / \mathrm{mouse})$ at 2 -week intervals. The peptides were mixed with an equal volume of Freund's complete adjuvant (Sigma, USA) in the initial immunization, and with Freund's incomplete adjuvant (Sigma) in the second and third immunizations. The 2 mice with the highest antibody titers specific for ST and $\mathrm{SH}$, as determined by indirect enzyme-linked immunosorbent assay (ELISA), were boosted by a tail vein injection 3 days before cell fusion. Feeder layer cells of peritoneal macrophages from normal BALB/c mice were seeded 1 day prior to fusion. Spleen cells from the boosted mice were fused with Sp2-0 myeloma cells (American Type Culture Collection) (10) at a 5:1 ratio using polyethylene glycol (avg. Mr: 3350). Supernatants from individual hybridomas were screened by indirect ELISA for their reactivity with the peptides ST and $\mathrm{SH}$. Positive hybridoma lines were isolated by limited serial dilution. For limited serial dilution, hybridomas from one parental generation were added to a 96-well plate at one cell per well. The culture supernatant containing the growing hybridomas was repeatedly screened by indirect ELISA and subcloned by limited serial dilution until all picked hybridomas were positive. The selected clones were then injected intraperitoneally into BALB/C mice to produce ascitic fluid. The mAbs were purified from the ascites using a protein G-Sepharose column (Pierce) and isotyped using a mouse monoclonal isotyping kit (AbD Serotec, USA). The isotyping and purification procedures were performed according to manufacturer instructions.

\section{Indirect ELISA}

Serological screening of the mice and positive hybridoma culture supernatants was performed by indirect ELISA to determine the highest antibody titer. Peptides ST and SH without KLH (30 ng/well; $100 \mu \mathrm{L}$ ) were applied to high-binding polystyrene plates (Corning Life Sciences, USA) and incubated overnight at $4^{\circ} \mathrm{C}$. After five washes with PBS-Tween buffer (0.05\% Tween-20 in PBS), the wells were blocked with $300 \mu \mathrm{L} 1 \%$ BSA for $2 \mathrm{~h}$ at room temperature and then washed again. Individual hybridoma culture supernatants (1:1 dilution with PBS; $100 \mu \mathrm{L}$ ) were added, followed by incubation at $37^{\circ} \mathrm{C}$ for $1 \mathrm{~h}$. Subsequently, the plates were thoroughly washed. Following incubation with $100 \mu \mathrm{L}$ goat anti-mouse IgG polyclonal antibodies coupled with horse radish peroxidase (HRP) (Abcam, USA) at $37^{\circ} \mathrm{C}$ for $1 \mathrm{~h}(1: 5000)$, the wells were developed with tetramethylbenzidine substrate for $5 \mathrm{~min}$ at room temperature, and the reactions were then stopped using $100 \mu \mathrm{L}$ stop solution. The plates were read in a Bio-Rad ELx800 microplate reader (USA) at $450 \mathrm{~nm}$.

Indirect ELISA was used to identify the purified mAbs. Peptides ST and SH (30 ng/well) without KLH were coated onto high-binding polystyrene plates. Dilutions of the purified mAbs were then added to the wells to detect reactivity. The procedure was performed as described above.

\section{Western blotting}

Cell lysates ( $50 \mu$ g protein/sample) of the MRC-5, Towne, and AD169 strains were collected; MRC- 5 cell lysates were used as a negative control. The proteins were denatured at $100^{\circ} \mathrm{C}$ for $10 \mathrm{~min}$ under reducing conditions and then separated by $10 \%$ SDS-PAGE and transferred to PVDF membranes ( $0.45 \mu \mathrm{m}$; Millipore, USA). Purified mAbs were used as the primary antibody (1 mg/mL, 1:5000), followed by HRP-conjugated goat anti-mouse IgG polyclonal antibodies (1:5000). A mouse mAb against gB (Novus Biologicals, USA) was used as a control. The reaction was developed using ECL reagent (Millipore) and analyzed with the VersaDoc5000 imaging system (Bio-Rad).

\section{Immunoprecipitation \\ HCMV gB was immunoprecipitated (IP) using purified}


mAbs. Individual samples of cell lysates of the Towne and AD169 strains (150 $\mathrm{\mu g} / \mathrm{sample})$ were incubated at $4^{\circ} \mathrm{C}$ overnight with the purified mAbs $(2 \mu \mathrm{g} / \mathrm{sample})$ coupled to protein G-Sepharose beads. An MRC-5 cell lysate was used as a negative control and a mouse mAb against gB (Novus Biologicals) was used as a positive control. Rabbit anti-HCMV gB polyclonal antibodies (HuaAn Biotechnology Co.) were used as the primary antibody (1:2500), followed by HRP-coupled goat anti-rabbit IgG antibodies (HuaAn Biotechnology Co.). The reaction was developed as described in Western blotting.

\section{Immunohistochemical (IHC) staining}

For IHC staining, $4 \times 10^{4} \mathrm{MRC}-5$ cells were seeded on glass coverslips in six-well plates and incubated overnight. The cells were then infected with HCMV strains Towne and AD169 at an $\mathrm{MOI}$ of 1.0 for 3 days at $37^{\circ} \mathrm{C}$. Normal MRC- 5 cells were used as a negative control. The cells were then fixed in cold acetone for $1 \mathrm{~h}$ followed by three 5-min washes with TBS. Viral gB proteins were detected using purified mAbs $(0.25 \mu \mathrm{g} / \mathrm{slide})$. HRP-conjugated goat anti-mouse IgG polyclonal antibodies were used as the secondary antibody (1:5000) followed by reagents from the EnVision System (Dako, USA). IHC staining was performed according to manufacturer instructions. Brown-stained cells were considered to be positive, and blue-stained cells, negative.

\section{Detection of gB and pp65 antigen in allo-HSCT patients}

Peripheral blood leukocytes (PBLs) from 92 allo-HSCT patients were subjected to IHC staining to detect the $\mathrm{gB}$ and pp65 antigens. PBLs from 3 HCMV-seronegative healthy volunteers, 3 Herpes simplex virus (HSV)-infected individuals, and 3 Epstein-Barr virus (EBV)-infected individuals as confirmed by real-time PCR using LightCycler ${ }^{\circledR} \mathrm{HSV}$ and EBV Quant Kits (Roche Diagnostics, USA), were detected by the purified mAbs as controls. Research procedures for all specimen collections were approved by the Ethics Committee of Zhejiang University. Leukocytes were fixed on polylysine-coated slides ( $5 \times 10^{4}$ cells/slide) as described above. The purified mAbs and a pp65 mAb (Dako) were used as primary antibody. Staining scores were calculated as the number of positive cells $/ 5 \times 10^{4}$ white blood cells. All slides were scored by two observers who were blind to the patient and mAb used.

\section{Statistical analysis}

All experiments were performed in triplicate. The data were analyzed using SPSS version 16.0. Positivity rates and differences in HCMV gB detection between the mAbs were examined by paired-crosstabs McNemar and Wilcoxon rank-sum tests. Spearman correlation was used to evaluate the correlation between the detection of $\mathrm{gB}$ and pp65. $\mathrm{P}<$ 0.05 was taken to indicate a significant difference.

\section{Results}

\section{Generation of mAbs}

Peptides were used to produce mAbs specific for HCMV $\mathrm{gB}$. The antibodies produced were screened by indirect ELISAs. Hybridoma lines of ST-3H4E11D3A1H6 (named ZJU-FH6) and SH-6E1F9D1E6 (named ZJU-FE6) were selected for their positive reactivity. The $\mathrm{mAbs}$ were purified from mouse ascites using a Protein G-Sepharose column. The isotypes of the mAbs, IgG1 with a $\mathrm{k}$ chain (ZJU-FH6) and IgG2a with a $\mathrm{k}$ chain (ZJU-FE6), were determined using a mouse monoclonal isotyping kit (Figure 1). The final indirect ELISA screening of ZJU-FH6 and ZJU-FE6 is shown in Figure 1.

\section{Characterization of ZJU-FH6 and ZJU-FE6 mAbs}

ZJU-FH6 and ZJU-FE6 displayed specific binding affinities for peptides ST and $\mathrm{SH}$, respectively (Figure 2). The original concentration of ZJU-FH6 was $4 \mathrm{mg} / \mathrm{mL}$ and of ZJU-FE6 was $1.2 \mathrm{mg} / \mathrm{mL}$. ELISA revealed that the titers of ZJU-FH6 and ZJU-FE6 were high, as they were detectable at dilution of $1: 60,000$ and $1: 240,000$, respectively. The reactivity of the mAbs to $\mathrm{HCMV} g B$ as demonstrated by Western blotting under reducing conditions is shown in Figure 3A. Both mAbs showed a protein band in either lane Towne or lane AD169 at the same position on the gel as the control antibody, where no positive band was shown in lane MRC-5. An IP assay was performed to determine their ability to recognize native gB (Figure $3 \mathrm{~B}$ ). Lysates of the Towne and AD169 strains were immunoprecipitated with the mAbs, and an MRC-5 cell lysate was immunoprecipitated as a negative control. The $\mathrm{mAbs}$ recognized native $\mathrm{gB}$ of the Towne and AD169 strains, consistently with the control antibody. Western blotting and IP indicated that both the ZJU-FH6 and ZJU-FE6 mAbs recognized denatured and native Towne and AD169 gB.

\section{Immunocytochemical (IHC) staining}

IHC staining was performed using the ZJU-FH6 and ZJU-FE6 mAbs to observe the intracellular gB. MRC-5 cells were infected with strains Towne and AD169, and normal MRC-5 cells were used as a negative control (Figure 4). Negative cells were stained blue, while positive cells infected with the Towne and AD169 strains were stained brown. The two mAbs targeted both cells infected with the Towne and AD169 strains.

\section{Detection of gB and pp65 antigen in allo-HSCT patients}

The ZJU-FH6 and ZJU-FE6 mAbs were used for IHC staining to detect HCMV gB antigen in PBLs from 92 alloHSCT patients. Cells stained brown were considered to be positive, and those stained blue were considered to be negative (Figure 5). Negative cells were observed in specimens from HCMV-seronegative healthy volunteers, 

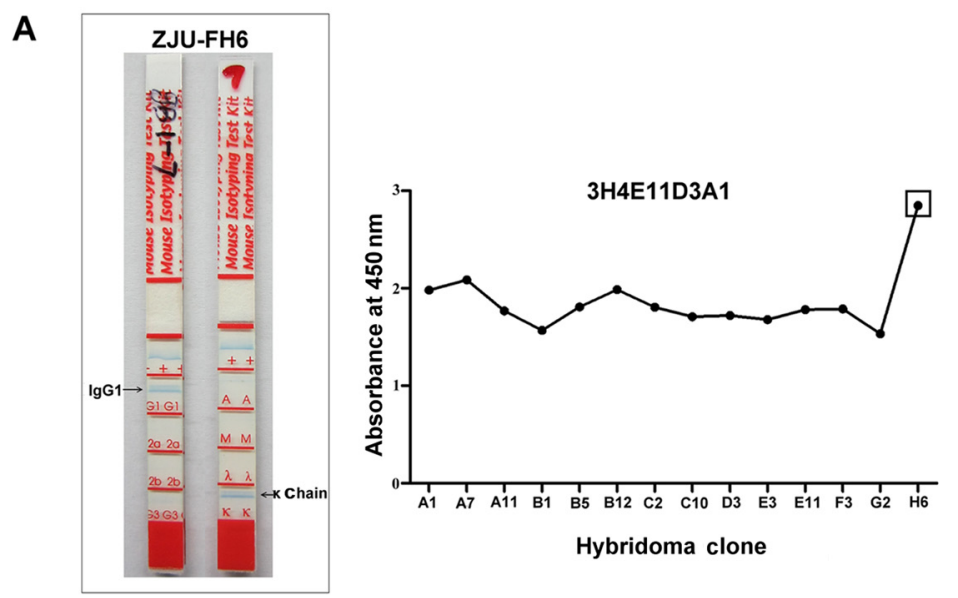

B
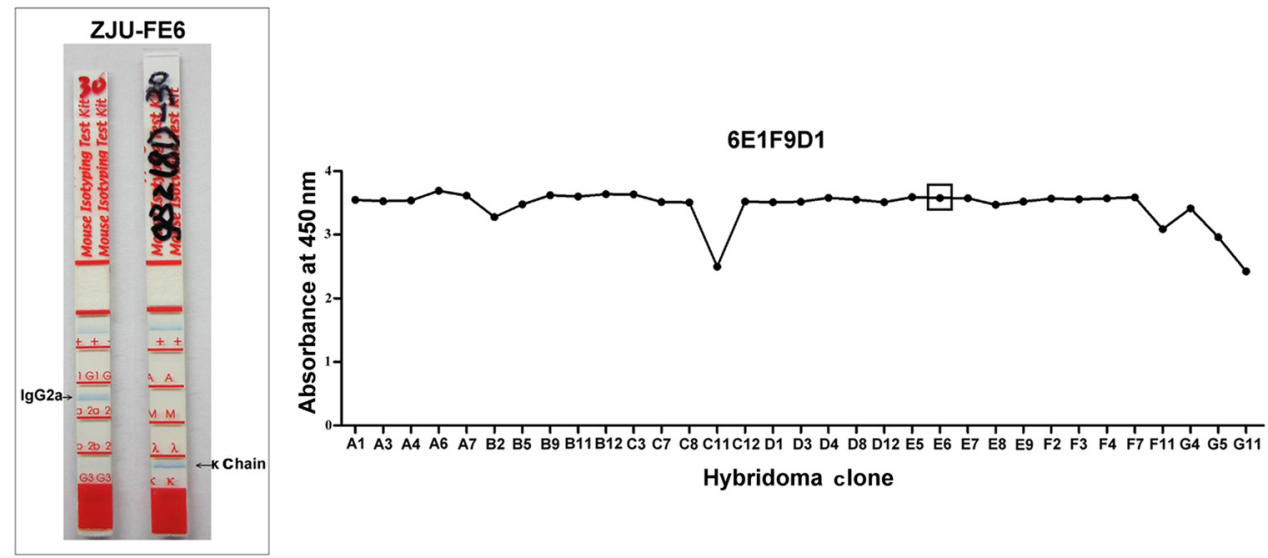

Figure 1. Isotypes and final indirect ELISA screening of mAbs ZJU-FH6 $(A)$ and ZJU-FE6 $(B)$. The isotypes of the mAbs were identified with a mouse monoclonal isotyping kit. The isotype of the mAb ZJU-FH6 was an IgG1 with a $\mathrm{K}$ chain and ZJU-FE6 was an IgG2a with a $\mathrm{K}$ chain. For indirect ELISA screening, peptides ST and SH without keyhole limpet hemocyanin ( $30 \mathrm{ng} /$ well) were applied to high-binding polystyrene plates. Individual hybridoma culture supernatants (1:1 dilution with PBS) were added to detect reactivity.

A

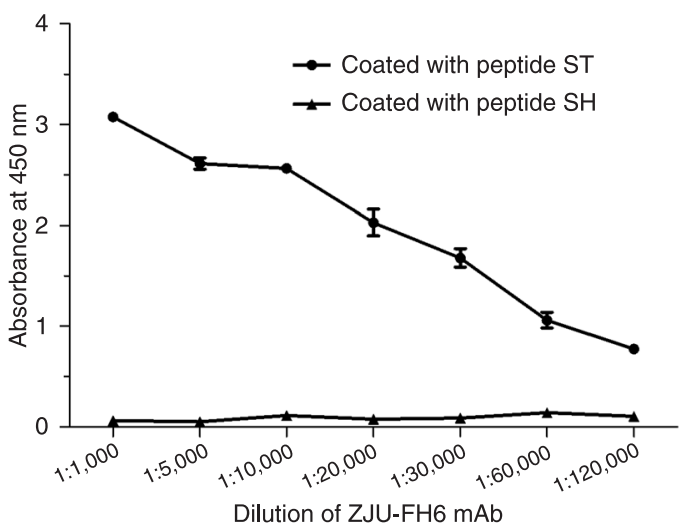

B

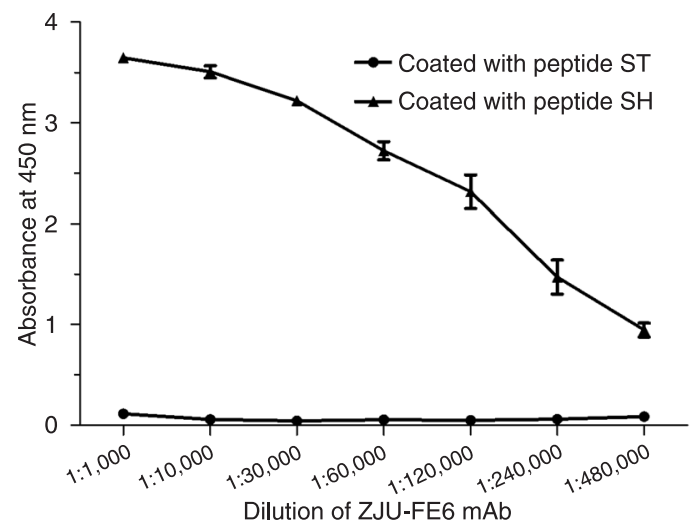

Figure 2. ELISA analysis of mAbs ZJU-FH6 $(A)$ and ZJU-FE6 (B). Peptides ST and SH without keyhole limpet hemocyanin (30 ng/well) were coated onto high-binding polystyrene plates. Dilutions of ZJU-FH6 and ZJU-FE6 were then added to detect reactivity. The original concentrations were $4 \mathrm{mg} / \mathrm{mL}$ for $\mathrm{mAb}$ ZJU-FH6 and $1.2 \mathrm{mg} / \mathrm{mL}$ for mAb ZJU-FE6. 

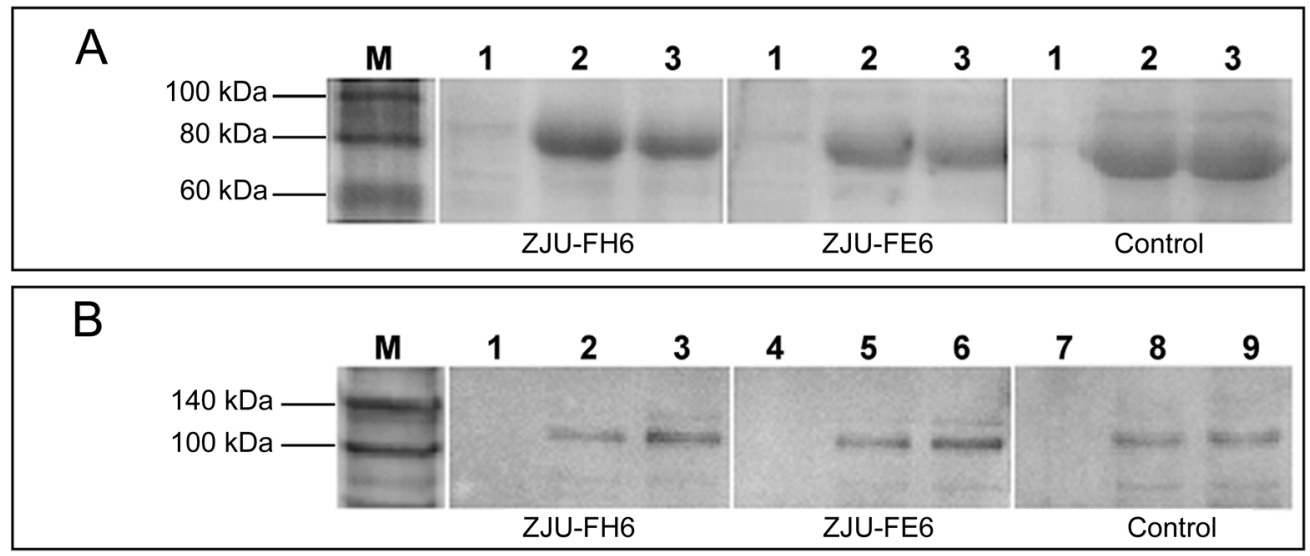

Figure 3. Western blotting and immunoprecipitation analysis of mAbs ZJU-FH6 and ZJU-FE6. A, Western blotting was carried out for cell lysates ( $50 \mu \mathrm{g} / \mathrm{sample}$ ) of the MRC-5, Towne, and AD169 strains. ZJU-FH6 and ZJU-FE6 were used as primary antibody $(1 \mathrm{mg} / \mathrm{mL}, 1: 5000)$. A mouse $\mathrm{mAb}$ against $\mathrm{gB}$ (Novus Biologicals) was used as a control. Lane 1 = MRC-5; lane 2 = Towne strain; lane 3 = AD169 strain. B, Immunoprecipitation was carried out to immunoprecipitate HCMV gB using ZJU-FH6 and ZJU-FE6 $(2 \mu \mathrm{g} / \mathrm{sample})$. Samples of cell lysates of the Towne and AD169 strains (150 $\mathrm{\mu g} / \mathrm{sample}$ ) were incubated with ZJU-FH6 (lanes 1, 2, and 3) and ZJU-FE6 (lanes 4, 5 and 6) coupled to protein G-Sepharose beads. A mouse mAb (lanes 7, 8 and 9) against gB (Novus Biologicals) was used as a control. Rabbit anti-human cytomegalovirus $\mathrm{gB}$ polyclonal antibodies was used as primary antibody (1:2500). Lanes 1, 4, and 7 = MRC-5; lanes 2, 5, and 8= Towne strain; lanes 3, 6, and $9=$ AD169 strain.

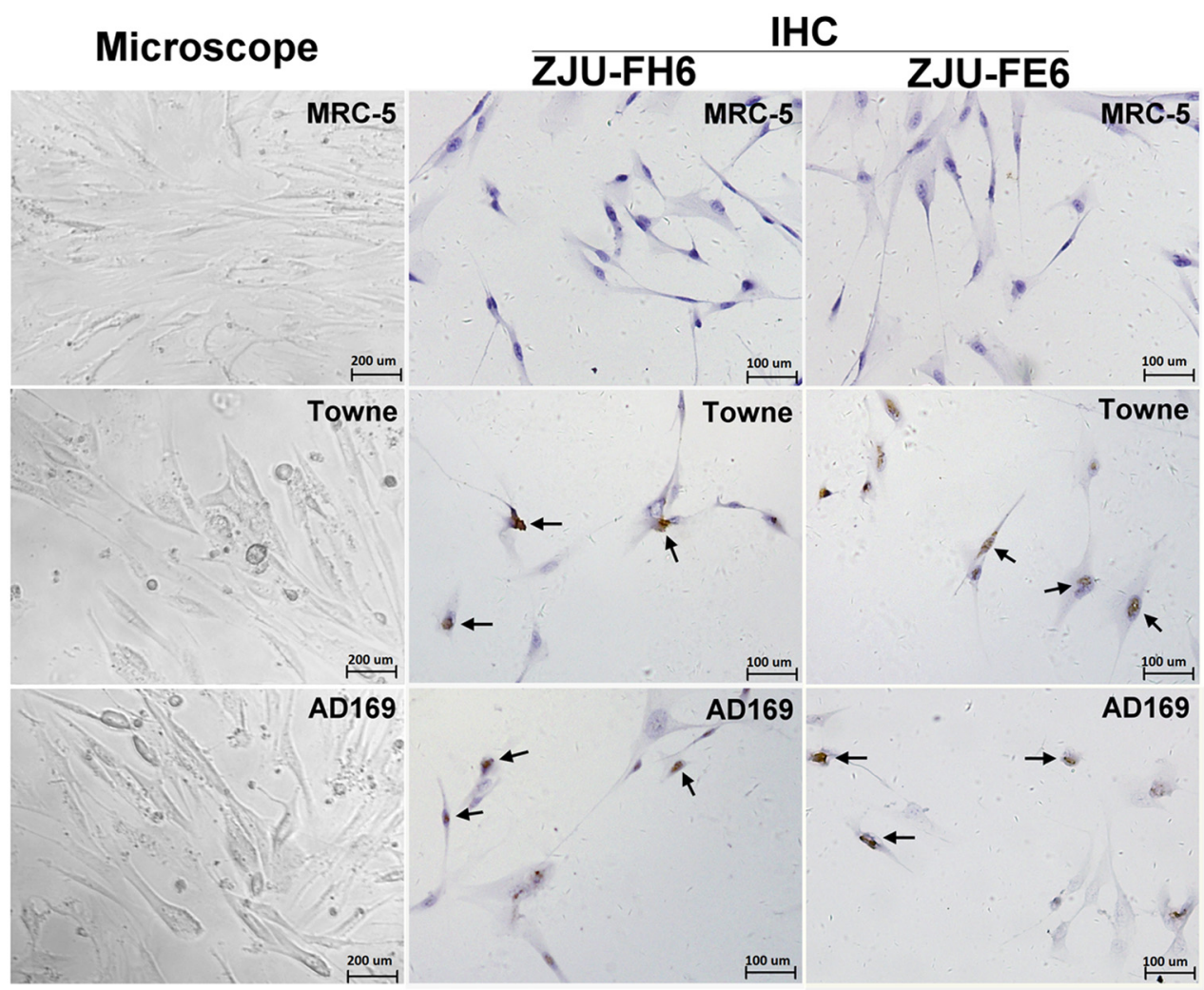

Figure 4. Immunohistochemical (IHC) staining of human cytomegalovirus (HCMV)-infected MRC-5 cells using mAbs ZJU-FH6 and ZJU-FE6. Normal MRC- 5 cells were infected with HCMV strains Towne and AD169 at an MOI of 1.0 for 3 days at $37^{\circ} \mathrm{C}$. For IHC staining, $4 \times 10^{4} \mathrm{MRC}-5$ cells were seeded on glass coverslips in six-well plates and infected with HCMV strains Towne and AD169. Viral gB proteins were detected using mAbs ZJU-FH6 and ZJU-FE6. Cells stained brown were considered to be positive, and those stained blue were negative. The arrows point to the positive cells. 


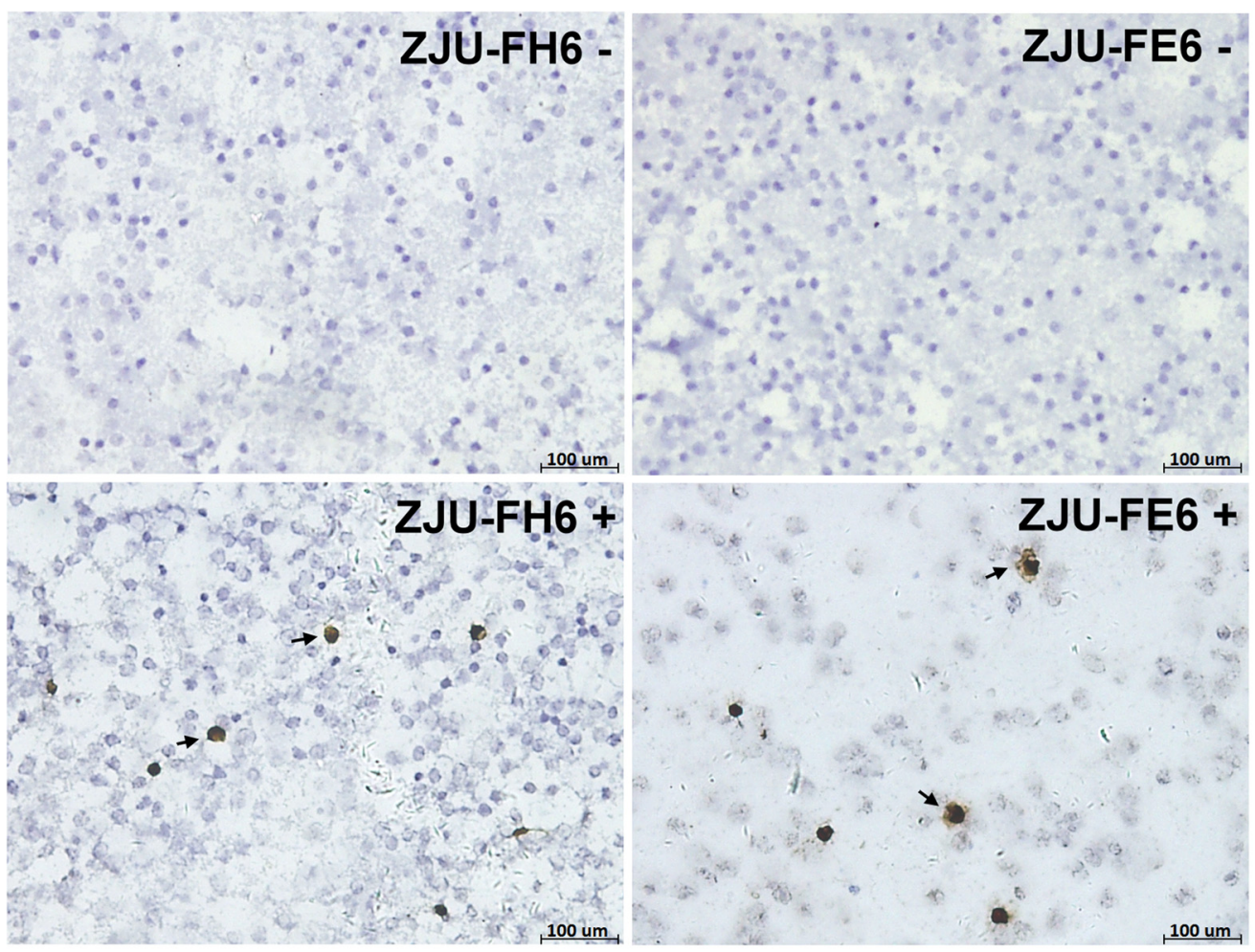

Figure 5. Immunohistochemical staining of peripheral blood leukocytes (PBLs) from allo-HSCT patients using mAbs ZJU-FH6 and ZJU-FE6. Cells stained dark brown were considered to be positive (arrows), and those stained blue were negative. Staining score was calculated as the number of positive cells $/ 5 \times 10^{4}$ WBC.

and HSV- or EBV-infected patients. The gB positivity rates determined using the ZJU-FH6 and ZJU-FE6 mAbs were $62.0(57 / 92)$ and $63.0 \%(58 / 92)$, respectively. No significant difference in positivity rate $(P=1.000)$ or population difference $(Z=-1.021, P=0.307)$ was found. The positive rate of pp65 antigen of 92 allo-HSCT patients was $75.0 \%$ (69/92). There was a significant correlation between the level of pp65 antigen and gB antigen detected by ZJU-FH6 $(r=0.781, P$ $=0.000)$ or ZJU-FE6 $(r=0.734, \mathrm{P}=0.000)$.

\section{Discussion}

HCMV is ubiquitous and latent in the human population and approximately $60 \%$ of adults in developed countries and $100 \%$ of adults in developing countries are seropositive (11). Infection with the virus in transplant patient is life-threatening. For instance, HCMV infection is associated with organ rejection, graft dysfunction, fungal and bacterial infections in solid organ transplant recipients (12). Timely and specifically detection of HCMV infection is essential for effective therapy of transplant recipients. Although assays have been introduced into diagnostic laboratories on HCMV infection detection and monitoring, they are far from sufficient.

The protein gB represents a target for diagnosis and treatment in view of the role it plays in the virus lifetime. Research on $\mathrm{gB}$ will facilitate the understanding of the pathogenic mechanisms of HCMV infection, the development of detection, and the selection of epitopes for vaccines. Monoclonal antibodies have tremendous applications in diagnosis, therapeutics, and targeted drug delivery systems (13). Antibodies to HCMV gB have been studied by a number of investigators (14-16), whereas few have focused on the diagnostic importance of anti-HCMV gB antibodies. The gB-neutralizing antibodies have been shown to inhibit infection during the initial attachment step, and, even after attaching, neutralizing antibodies can inhibit various virus entry stages (8). It may be assumed that $\mathrm{gB}$ antigen would be reduced or even undetectable where gB-neutralizing antibodies exist.

In the present study, mouse mAbs to two different amino acid sequences of HCMV gB, named ZJU-FH6 and ZJUFE6, were generated and characterized by indirect ELISA, Western blotting, IP, and IHC staining. The prepared mAbs displayed high titers of specific binding affinities for the synthetic peptides (Figure 2). ZJU-FH6 and ZJU-FE6, are 
able to recognize both Towne and AD169 gB antigens in cellular lysates or infected cells (Figures 3 and 4).

Consequently, 92 allo-HSCT patients were tested using the two mAbs (Figure 5). When compared with pp65 antigenemia, a significant correlation between the level of pp65 antigen and gB antigen detected by ZJU-FH6 ( $r=0.781)$ or ZJU-FE6 ( $r=0.734)$ was observed. The pp65 antigenemia assay, used for preemptive therapy, is considered to be the standard to validate in-house molecular biology-based detection methodologies $(17,18)$. The detected gB antigen was in accordance with the infectious level, indicating that the produced $\mathrm{mAbs}$ are capable of recognizing gB in alloHSCT patients in a reliable manner. On the other hand, this probably suggests that, although the immunogens were chosen for favorable immunogenicity, they may not represent protective epitopes. A greater number of samples should be tested in subsequent studies and the clinical diagnostic value of $\mathrm{gB}$ antigen could be estimated in further investigations.

Sequence variation has been observed in gB $(19,20)$; however, its contribution to pathogenesis remains unclear. Variation in gB has been used to classify HCMV genotypically, and may influence the clinical outcome $(21,22)$, probably by affecting the cell and organ tropism of HCMV (23), the virulence of different strains (24), and host lymphocyte subpopulations and cytokine levels (25). In contrast, a lack of correlation between gB types and clinical outcomes (26-28) or a response to therapy (29) has also been reported. Virus

\section{References}

1. Gratama JW, Cornelissen JJ. Diagnostic potential of tetramer-based monitoring of cytomegalovirus-specific CD8+ T lymphocytes in allogeneic stem cell transplantation. Clin Immunol 2003; 106: 29-35.

2. Isaacson MK, Compton T. Human cytomegalovirus glycoprotein $B$ is required for virus entry and cell-to-cell spread but not for virion attachment, assembly, or egress. J Virol 2009; 83: 3891-3903.

3. Navarro D, Paz P, Tugizov S, Topp K, La Vail J, Pereira L. Glycoprotein B of human cytomegalovirus promotes virion penetration into cells, transmission of infection from cell to cell, and fusion of infected cells. Virology 1993; 197: 143158.

4. Berencsi K, Rando RF, deTaisne C, Paoletti E, Plotkin SA, Gonczol E. Murine cytotoxic $T$ cell response specific for human cytomegalovirus glycoprotein B (gB) induced by adenovirus and vaccinia virus recombinants expressing $\mathrm{gB}$. J Gen Virol 1993; 74 (Part 11): 2507-2512.

5. Hopkins JI, Fiander AN, Evans AS, Delchambre M, Gheysen D, Borysiewicz LK. Cytotoxic T cell immunity to human cytomegalovirus glycoprotein B. J Med Virol 1996; 49: 124131.

6. Navarro D, Lennette E, Tugizov S, Pereira L. Humoral immune response to functional regions of human cytomegalovirus glycoprotein B. J Med Virol 1997; 52: 451-459.

7. Lucht E, Sundqvist VA, Linde A, Bratt G, Sandstrom E, variants may be generated by homologous recombination (20). Frequent intragenic variation in $\mathrm{gB}$ and infection with multiple gB subtypes have rendered breakthroughs in the diagnosis, treatment, or prevention of HCMV infection problematic. Moreover, reinfection and multiple infections with HCMV gB subtypes occur, and this is thought to result in an unfavorable prognosis (25,30). An ELISA (31) has been reported to detect strain-specific antibody responses using recombinant antigens based on polymorphic antibody binding sites in $\mathrm{gH}$ (glycoprotein $\mathrm{H}$ ) and $\mathrm{gB}$ from the Towne and AD169 strains. However, no apparent difference was found between ZJU-FH6 and ZJU-FE6 through identification and detection, demonstrating that different HCMV strains of $\mathrm{gB}$ have some same epitopes. The synthetic peptides may not contain strain-specific epitopes. Future research should concentrate on epitope screening, which could contribute to the production of HCMV-neutralizing antibodies and facilitate HCMV vaccine development.

\section{Acknowledgments}

Research supported by the National Natural Science Foundation of China (\#30872239), Cooperation of Zhejiang Province and Ministry of Public Health of China Research Foundation (\#WKJ2009-2-023), and the Technology Team for Major Infectious Diseases Prevention Control, Warning and Treatment (\#2009R50041).

Heimdahl A, et al. Presence of autologous neutralizing antibodies against cytomegalovirus (CMV) in serum of human immunodeficiency virus type 1-infected patients shedding CMV in saliva. J Infect Dis 1994; 169: 1096-1100.

8. Gicklhorn D, Eickmann M, Meyer G, Ohlin M, Radsak K. Differential effects of glycoprotein B epitope-specific antibodies on human cytomegalovirus-induced cell-cell fusion. J Gen Virol 2003; 84: 1859-1862.

9. Straschewski S, Warmer M, Frascaroli G, Hohenberg H, Mertens T, Winkler M. Human cytomegaloviruses expressing yellow fluorescent fusion proteins - characterization and use in antiviral screening. PLoS One 2010; 5: e9174.

10. Kari B, Lussenhop N, Goertz R, Wabuke-Bunoti M, Radeke $\mathrm{R}$, Gehrz R. Characterization of monoclonal antibodies reactive to several biochemically distinct human cytomegalovirus glycoprotein complexes. J Virol 1986; 60: 345-352.

11. Bendiksen S, Van Ghelue M, Rekvig OP, Gutteberg T, Haga $\mathrm{HJ}$, Moens U. A longitudinal study of human cytomegalovirus serology and viruria fails to detect active viral infection in 20 systemic lupus erythematosus patients. Lupus 2000; 9: 120-126.

12. Allice T, Cerutti F, Pittaluga F, Varetto S, Franchello A, Salizzoni $\mathrm{M}$, et al. Evaluation of a novel real-time PCR system for cytomegalovirus DNA quantitation on whole blood and correlation with pp65-antigen test in guiding pre-emptive antiviral treatment. $J$ Virol Methods 2008; 148: 9-16. 
13. Siddiqui MZ. Monoclonal antibodies as diagnostics; an appraisal. Indian J Pharm Sci 2010; 72: 12-17.

14. Rasmussen L, Cowan CM. Neutralizing antibody to gB2 human cytomegalovirus does not prevent reactivation in patients with human immunodeficiency virus infection. $J$ Gen Virol 2003; 84: 1853-1857.

15. Zhang C, Pass RF. Detection of cytomegalovirus infection during clinical trials of glycoprotein B vaccine. Vaccine 2004; 23: $507-510$

16. Yue Y, Zhou SS, Barry PA. Antibody responses to rhesus cytomegalovirus glycoprotein $B$ in naturally infected rhesus macaques. J Gen Virol 2003; 84: 3371-3379.

17. Baldanti F, Revello MG, Percivalle E, Gerna G. Use of the human cytomegalovirus (HCMV) antigenemia assay for diagnosis and monitoring of HCMV infections and detection of antiviral drug resistance in the immunocompromised. $J$ Clin Virol 1998; 11: 51-60.

18. Boeckh M, Bowden RA, Gooley T, Myerson D, Corey L. Successful modification of a pp65 antigenemia-based early treatment strategy for prevention of cytomegalovirus disease in allogeneic marrow transplant recipients. Blood 1999; 93: 1781-1782.

19. Meyer-Konig U, Haberland M, von Laer D, Haller O, Hufert FT. Intragenic variability of human cytomegalovirus glycoprotein B in clinical strains. J Infect Dis 1998; 177: 11621169.

20. Haberland M, Meyer-Konig U, Hufert FT. Variation within the glycoprotein $\mathrm{B}$ gene of human cytomegalovirus is due to homologous recombination. J Gen Virol 1999; 80 (Part 6): 1495-1500.

21. Roubalova K, Strunecky O, Zufanova S, Prochazka B, Vitek A. [Genotyping of viral glycoprotein $B(g B)$ in hematopoietic stem cell transplant recipients with active cytomegalovirus infection: analysis of the impact of gB genotypes on the patients' outcome]. Epidemiol Mikrobiol Imunol 2010; 59: 92-99.

22. Torok-Storb B, Boeckh M, Hoy C, Leisenring W, Myerson D,
Gooley T. Association of specific cytomegalovirus genotypes with death from myelosuppression after marrow transplantation. Blood 1997; 90: 2097-2102.

23. Meyer-Konig U, Vogelberg C, Bongarts A, Kampa D, Delbruck R, Wolff-Vorbeck G, et al. Glycoprotein B genotype correlates with cell tropism in vivo of human cytomegalovirus infection. J Med Virol 1998; 55: 75-81.

24. Coaquette A, Bourgeois A, Dirand C, Varin A, Chen W, Herbein $\mathrm{G}$. Mixed cytomegalovirus glycoprotein $\mathrm{B}$ genotypes in immunocompromised patients. Clin Infect Dis 2004; 39 : 155-161.

25. Correia-Silva JF, Resende RG, Arao TC, Abreu MH, Teixeira $\mathrm{MM}$, Bittencourt $\mathrm{H}$, et al. HCMV gB genotype and its association with cytokine levels in hematopoietic stem cell transplantation. Oral Dis 2011; 17: 530-537.

26. Sarcinella L, Mazzulli T, Willey B, Humar A. Cytomegalovirus glycoprotein B genotype does not correlate with outcomes in liver transplant patients. J Clin Virol 2002; 24: 99-105.

27. Vogelberg C, Meyer-Konig U, Hufert FT, Kirste G, von Laer D. Human cytomegalovirus glycoprotein B genotypes in renal transplant recipients. J Med Virol 1996; 50: 31-34.

28. Aquino VH, Figueiredo LT. High prevalence of renal transplant recipients infected with more than one cytomegalovirus glycoprotein B genotype. J Med Virol 2000; 61: 138-142.

29. Humar A, Kumar D, Gilbert C, Boivin G. Cytomegalovirus (CMV) glycoprotein B genotypes and response to antiviral therapy, in solid-organ-transplant recipients with CMV disease. J Infect Dis 2003; 188: 581-584.

30. Pang X, Humar A, Preiksaitis JK. Concurrent genotyping and quantitation of cytomegalovirus gB genotypes in solidorgan-transplant recipients by use of a real-time PCR assay. J Clin Microbiol 2008; 46: 4004-4010.

31. Novak Z, Ross SA, Patro RK, Pati SK, Reddy MK, Purser $M$, et al. Enzyme-linked immunosorbent assay method for detection of cytomegalovirus strain-specific antibody responses. Clin Vaccine Immunol 2009; 16: 288-290. 